\title{
Validitas dan Reliabilitas Ages \& Stages Questionnaire: Social-Emotional 2 versi Indonesia
}

Citra Cesilia, Diah Asri Wulandari, Meita Dhamayanti

Departemen Ilmu Kesehatan Anak Fakultas Kedokteran Universitas Padjadjaran / Rumah Sakit Umum Pusat Hasan Sadikin, Bandung

Latar belakang. Identifikasi dini gangguan sosial, emosi, dan perilaku merupakan hal penting untuk anak usia 3 tahun kebawah. Saat ini belum ada instrumen skrining untuk kelompok usia tersebut.

Tujuan. Untuk menilai validitas dan reliabilitas Kuesioner Ages \& Stages Questionnaire: Social-Emotional 2 versi Indonesia

Metode. Studi ini merupakan studi potong-lintang yang dilakukan pada periode Agustus 2018 hingga November 2018 di Puskesmas Garuda, Bandung, Indonesia.

Hasil. Sebanyak 659 dari 689 anak-anak terlibat pada studi ini. Hasil Cronbach's alpha berkisar 0,486-0,779 sedangkan metode Split-half berkisar 0,08-0,91. Koefisien korelasi studi ini sebesar 0,68-0,95.

Kesimpulan. Uji validitas ASQ:SE-2 pada usia 12-36 bulan memenuhi kriteria validitas. Uji reliabilitas menggunakan Cronbach alpha pada kelompok usia 18, 24, dan 30 bulan memiliki reliabilitas yang cukup baik, adapun pada kelompok usia 12 bulan hasil uji reliabilitas dibawah cut-off point yang menunjukkan hasil tidak reliabel. Sari Pediatri 2021;22(6):343-50

Kata kunci: ASQ:SE-2, usia dini, sosial emosional

\section{Validity and Reliability of Ages \& Stages Questionnaire: Social-Emotional 2 Indonesian version}

Citra Cesilia, Diah Asri Wulandari, Meita Dhamayanti

Background. Early identification of children below 3 years of age with social and emotional behavior problems is essential. There are no tools for that age available in Indonesia.

Objective. To assess validity and reliability of Ages and Stages Questionnaires: Social-Emotional (ASQ:SE-2) Indonesian version.

Methods. This is a cross-sectional study conducted from August to November 2018 at Puskesmas Garuda, Bandung, Indonesia. The Chronbach's alpha and Split-half tests were used to analyze the reliability, while the Spearman correlation was performed for the validity test.

Result. A total of 659 of 689 parents of children were included in the study. The Cronbach's alpha score varied between $0.486-0.779$ while The Split-half method ranged from 0.08-0.91. The correlation coefficient was 0.68-0.95.

Conclusion. The validity test of ASQ: SE-2 at 12-36 months of age has met the valid criteria. The reliability using Cronbach alpha in the 18,24, and 30 month age group has fairly good reliability, however, in the 12 month age group the results were not viable. Sari Pediatri 2021;22(6):343-50

Keywords: ASQ:SE-2, early age, social emotional

Alamat korespondensi: Citra Cesilia. Departemen Ilmu Kesehatan Anak Fakultas Kedokteran Universitas Padjadjaran Jl. Pasteur No.38, Bandung 4016.. Email: citra. ika2015@gmail.com 
T Tahun-tahun awal kehidupan memberikan kesempatan unik untuk perkembangan yang sehat. Pada periode ini terjadi perkembangan otak yang pesat. ${ }^{1}$ Penelitian pada anak usia dini telah menunjukkan pentingnya dampak 5 tahun pertama seorang anak untuk perkembangan sosio-emosionalnya. Pengalaman yang buruk pada masa ini dapat mengganggu kesehatan mental dan memengaruhi perkembangan kognitif, perilaku dan sosio-emosional anak. ${ }^{1,2}$ Gangguan sosial emosional pada anak merupakan masalah kesehatan yang penting karena selain prevalensi kasus yang tinggi juga berdampak terhadap anak itu sendiri, keluarga, dan masyarakat. ${ }^{2}$ Sekitar 9,5-14,2\% anak usia kurang dari 5 tahun mengalami gangguan sosio-emosional yang berdampak negatif pada fungsi, perkembangan, dan kesiapan sekolah mereka, tetapi kurang dari satu persen dari gangguan perilaku dan emosi pada anak usia yang teridentifikasi. ${ }^{2,3}$

Kuesioner ages and stages questionnaires-social emotional (ASQ:SE) merupakan instrumen skrining yang menjanjikan untuk digunakan pada usia yang lebih luas yaitu untuk digunakan pada usia yang lebih luas, dari lahir hingga usia 6 bulan. Kuesioner ini mencakup pengaturan diri, kepatuhan, dan kasih sayang antara domain lainnya. ${ }^{4,5}$ Kuesioner ini telah diadaptasi ke berbagai bahasa. Adapun Indonesia belum mempunyai instrumen skrining untuk mengidentifikasi dan menangani masalah perilaku pada anak secara dini. Untuk itu, ASQ-SE-2 versi Indonesia diharapkan dapat bermanfaat dalam diagnosis dan penanganan dini masalah perilaku pada anak usia 12-36 bulan. Tujuan penelitian ini adalah untuk menganalisis kesesuaian terjemahan ASQ:SE Bahasa Indonesia beserta reliabilitas dan validitasnya.

\section{Metode}

Studi ini merupakan studi observasional menggunakan desain potong-lintang yang dilakukan sejak 1 Agustus 2018 hingga 21 November 2018 pada wilayah kerja Puskesmas Garuda yang merupakan salah puskesmas jejaring Fakultas Kedokteran Universitas Padjadjaran.

Sebelumnya, penulis meminta izin kepada Brookes Publishing untuk melakukan uji validitas dan reliabilitas pada ASQ:SE-2 versi Indonesia. Setelah mendapatkan izin dan membayar biaya perizinan, studi ini melewati empat tahap. Tahap pertama, kuesioner diterjemahkan oleh 2 penerjemah. Penerjemahan dilakukan dari Bahasa Inggris ke Bahasa Indonesia dan begitupun sebaliknya. Tahap kedua, kedua terjemahan dipadukan yang oleh konsultan tumbuh kembang anak dengan tujuan untuk menyesuaikan kedua hasil terjemahan dan mengurangi perbedaan antara keduanya. Setelah itu, kedua terjemahan digabungkan. Tahap ketiga, dilakukan pengujian awal dengan minimum subjek sejumlah 52 pada tiap kelompok usia dan uji ulang (test-retest) dilakukan 1-3 minggu setelahnya terhadap subjek yang sukarela ikut serta.

Pengumpulan data dilakukan dalam tiga tahap. Tahap pertama, pengumpulan data sekunder yang diperoleh dari data kohort Puskesmas Garuda. Kriteria inklusi, di antaranya adalah orangtua anak berusia 9 bulan - 41 bulan 30 hari berdasarkan batas usia pada kuesioner aslinya. Subjek kemudian dibagi menjadi 5 kelompok, yaitu kelompok 12 bulan (usia 9 bulan-14 bulan 30 hari), 18 bulan (usia 15 bulan -20 bulan 30 hari), 24 bulan (usia 21 bulan -26 bulan 30 hari), 30 bulan (usia 27 bulan- 32 bulan 30 hari), dan 36 bulan (usia 33 bulan -41 bulan 30 hari) berdasarkan kelompok usia pada kuesioner aslinya. Kriteria inklusi lainnya adalah anak-anak dengan kelahiran full-term ( $>37$ minggu usia kehamilan), berat lahir $>2500$ gram, tidak ada faktor risiko persalinan, dan tidak ada gangguan perkembangan (mis, palsi serebral, retardasi mental, sindrom). Beberapa kriteria inklusi kemudian ditambahkan, yaitu orangtua atau wali harus dapat membaca dan menulis dengan baik, fasih berbahasa Indonesia, tidak memiliki riwayat gangguan psikiatri yang dikonfirmasi oleh dokter umum atau anggota keluarga lainnya, dan anak tidak dalam keadaan sakit. Tahap kedua, orangtua atau wali diwawancara oleh dokter umum yang telah dilatih cara wawancara oleh konsultan tumbuh kembang sebelumnya, dengan mengunjungi alamat subjek (door-to-door).

Semua responden merupakan seorang ibu. Asisten menjelaskan secara singkat mengenai tujuan dari studi, dan apabila bersedia untuk ikut serta, ibu harus menandatangani formulir informed consent. Fase ketiga adalah mengeksklusi subjek berdasarkan kriteria berikut, orangtua atau wali tidak mengisi kuesioner dengan lengkap, tidak tinggal serumah dengan anak, dan anak mengonsumsi obat yang dapat memengaruhi perilaku (obat anti-epilepsi, anxiolitik, ADHD, psikosis). Instrumen ini memiliki 22-36 item (bergantung pada 
usia), dengan pilihan berupa 'ya', 'kadang', atau 'belum pernah', yang membutuhkan sekitar 10-15 menit pengisian.

Data wawancara orangtua atau wali mengenai perkembangan anak bersifat rahasia. Responden diberikan hak untuk menolak berpartipasi dalam studi atau keluar dari studi. Pertimbangan etik dengan subjek manusia memenuhi standar Komite Etik Univeristas Padjadjaran Bandung.

Persentase digunakan untuk menggambarkan jumlah kuesioner berdasarkan kelompok usia, jenis kelamin, dan tingkat pendidikan orangtua. Uji reliabilitas dilakukan menggunakan Cronbach's Alpha dan metode split-half, sedangkan uji validitas dilakukan dengan menghitung korelasi antara nilai genap dan ganjil dengan nilai keseluruhan. Instrumen dinyatakan dapat dipercaya apabila nilai Cronbach's Alpha $\geq 0,60$ dan valid apabila koefisien korelasi Spearman Rank(r) $\geq 0,40$. Metode split-halfdilakukan sebagai uji alternatif untuk ruji reliabilitas apabila hasil uji Cronbach's alpha tidak memenuhi target reliabilitas yang sebelumnya sudah ditentukan $(\geq 0,60)$. Metode split-half bertujuan untuk meningkatkan konsistensi internal yang berhubungan dengan metode yang digunakan untuk menilai reliabilitas. ${ }^{6}$

\section{Hasil}

Sebanyak 659 dari 689 orangtua diikutsertakan ke dalam penelitian, 30 subjek dieksklusi dengan alasan 15 orang menolak diwawancara, 10 subjek loss to follow $u p$, dan 5 subjek pindah rumah. Data demografis seperti jenis kelamin, usia anak dan tingkat pendidikan orang tua tertera pada Tabel 1.

Reliabilitas kuesioner dinilai dengan menggunakan Cronbach's Alpha dan metode reliabilitas Split-half. Cronbach's Alpha dihitung berdasarkan variasi item

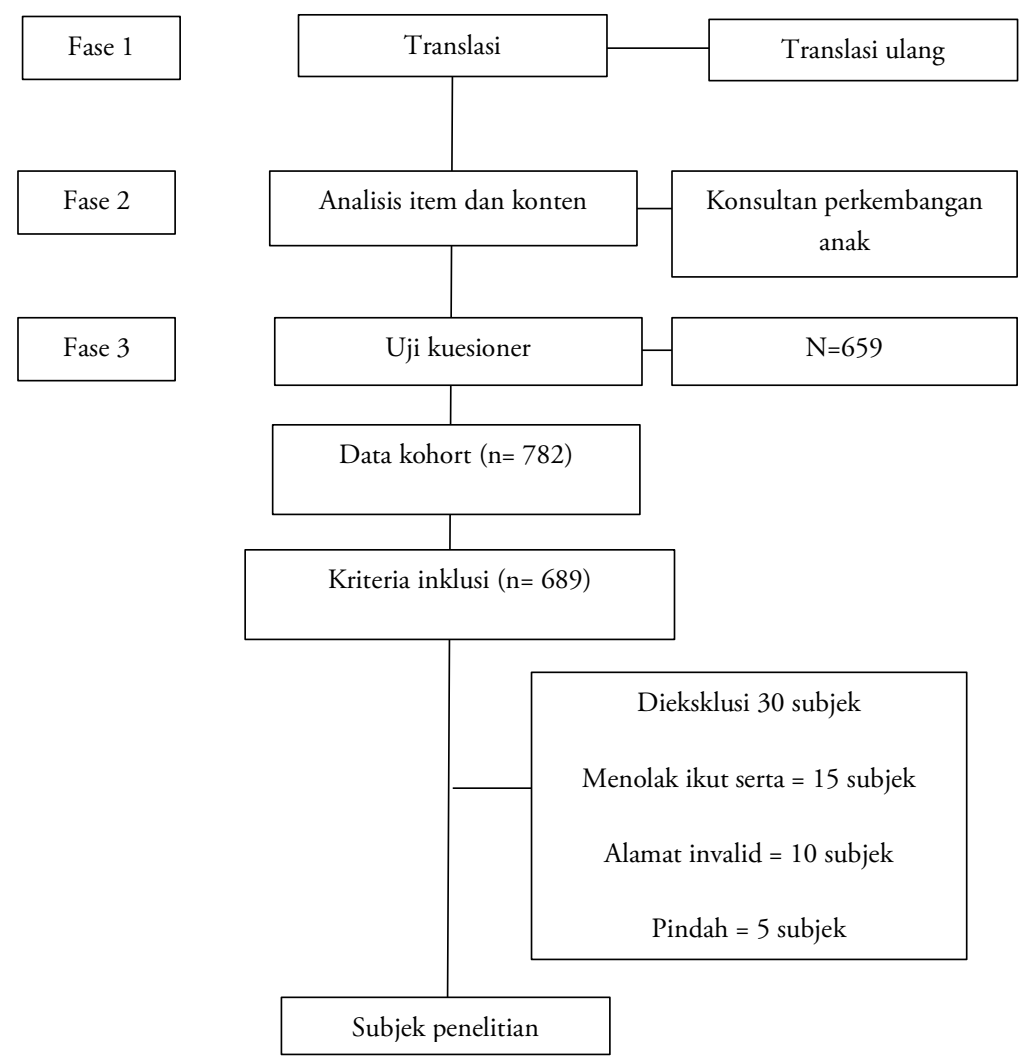

Gambar 1. Diagram alur penelitian 
individual dan variasi nilai total pada tiap kelompok usia ASQ:SE-2. Cronbach's Alpha memiliki rentang antara 0,486 pada kelompok usia 12 bulan hingga 0,779 pada kelompok usia 18 bulan. Metode split-half dilakukan setelah Cronbach's Alpha. Hasil metode splithalf memiliki rentang dari 0,086 pada kelompok usia 12 bulan hingga 0,919 pada kelompok anak usia 24 bulan.

Reliabilitas re-test dievaluasi menggunakan koefisien Pearson berdasarkan kuesioner yang diisi pada kunjungan pertama dan kedua yang berjarak 1-3 minggu oleh sekelompok orangtua yang setuju untuk berpartisipasi pada studi kedua. Pemberian jarak waktu pengisian antara kuesioner pertama dan kedua adalah untuk meminimalkan terjadinya pematangan perkembangan anak (tidak lebih dari 3 minggu). Di samping itu, sekaligus untuk memastikan adanya pemberian jarak waktu yang cukup antara kedua pengujian agar orangtua tidak mengisi kuesioner berdasarkan ingatan mereka mengenai jawaban kuesioner pertama. Koefisien Pearson pada usia keseluruhan memiliki rentang dari 0,919 pada 24 bulan, 0,897 pada 30 bulan, dan 0,843 pada 36 bulan.

Uji validitas dilakukan menggunakan koefisien korelasi Spearman Rank dengan membandingkan nilai item-genap dan item-ganjil terhadap nilai total. Hasil uji reliabilitas dan validitas untuk kuesioner ASQ: SE-2 dari 12 bulan hingga 36 bulan bersifat valid. Hasil uji validitas dan reliabilitas tertera pada Tabel 2.

Tabel 1. Karakteristik dasar anak yang diikutsertakan dalam penelitian

\begin{tabular}{lcc}
\hline Variabel & Frekuensi & Persentase \\
\hline Jenis kelamin & & \\
$\quad$ Laki-laki & 304 & 46,1 \\
$\quad$ Perempuan & 355 & 53,9 \\
Usia (bulan) & & \\
12 & 123 & 18,6 \\
18 & 150 & 22,8 \\
24 & 108 & 16,4 \\
30 & 114 & 17,4 \\
36 & 164 & 24,8 \\
Pendidikan orangtua & & \\
Sekolah Dasar (SD) & 70 & 10,6 \\
Sekolah Menengah Pertama (SMP) & 88 & 13,4 \\
Sekolah Menengah Atas (SMA) & 259 & 39,3 \\
Akademi/diploma (D3) & 223 & 33,8 \\
Sarjana 1 (S1) & 19 & 2,9 \\
\hline
\end{tabular}

Tabel 2. Validitas dan reliabilitas ASQ: SE-2 berdasarkan usia anak

\begin{tabular}{llccc}
\hline $\begin{array}{l}\text { Kuesioner untuk usia anak } \\
\text { (bulan) }\end{array}$ & Reliabilitas & \multicolumn{2}{c}{$\begin{array}{c}\text { Validitas } \\
\text { (koefisien korelasi) }\end{array}$} \\
\cline { 2 - 5 } & Cronbach Alpha & $\begin{array}{c}\text { Metode halfsplit / } \\
\text { korelasi pengukuran I dan } \\
\text { pengukuran II }\end{array}$ & $\begin{array}{c}\text { Item genap dengan } \\
\text { skor total }\end{array}$ & $\begin{array}{c}\text { Item ganjil } \\
\text { dengan skor total }\end{array}$ \\
\hline 12 & 0,486 & $\left.0,086^{*}\right)$ & 0,683 & 0,786 \\
18 & 0,779 & $\left.0,678^{*}\right)$ & 0,832 & 0,952 \\
24 & 0,678 & $\left.0,919^{* *}\right)$ & 0,729 & 0,871 \\
30 & 0,647 & $0,897^{* *}$ & 0,701 & 0,821 \\
36 & 0,619 & $0,843^{* *}$ & 0,693 & 0,765 \\
\hline
\end{tabular}




\section{Pembahasan}

Hasil konsistensi internal ASQ:SE-2 versi Indonesia menunjukkan hasil yang baik. Nilai tertinggi ditemukan pada kelompok usia 18 bulan, sedangkan terendah ditemukan pada kelompok usia 12 bulan. Sebuah studi yang dilakukan di Korea memiliki nilai Cronbach's alpha 0,56 pada usia 6 bulan hingga 0,77 pada usia 60 bulan, dengan rerata $0,68 .^{7}$ Kelompok usia 18, 24, dan 30 bulan menunjukkan nilai reliabilitas yang baik pada Cronbach's alpha, tetapi nilai menunjukkan hasil yang kurang baik pada kelompok usia 12 bulan. Hal ini serupa dengan hasil penelitian di Korea yang menyebutkan bahwa semakin tua usianya maka semakin baik reliabilitasnya. ${ }^{8}$

Hambatan utama dalam mengidentifikasi gangguan sosial dan emosional pada anak usia dini adalah tidak adanya penilaian psikometri yang baik, terjangkau, dan sesuai dengan budaya serta bahasa yang dapat mengidentifikasi gangguan sosial dan emosional secara akurat. ${ }^{4}$ Instrumen skrining telah banyak dipelajari di Amerika Serikat dan negara lain, tetapi hanya sedikit perhatian yang ditujukan pada bidang penelitian ini di Indonesia. ${ }^{9}$ Terdapat tiga alasan mengapa identifikasi dini pada gangguan sosial emosional penting dilakukan. Gangguan perilaku dan emosional dapat terjadi pada usia awal kehidupan, anak usia 2 tahun sudah dapat didiagnosis gangguan psikoligis. ${ }^{10-12}$ Saat ini belum ada instrumen skrining gangguan sosial dan emosional pada anak usia kurang dari 3 tahun. Oleh karena itu, hal ini menjadi hambatan dalam penanganan masalah perilaku pada anak usia kurang dari 3 tahun. Untuk itu, salah satu solusi adalah mengadaptasi instrumen yang sudah valid dan dapat dipercaya dari negara lain.

Kuesioner skrining gangguan sosial dan emosional anak yang tervalidasi di Indonesia salah satunya adalah Mental Emotional Problem Questionnaire yang dapat digunakan untuk anak usia lebih dari 36 bulan. Kuesioner ini tidak mencakup usia kurang dari 36 bulan sehingga gangguan yang terjadi pada anak usia kurang dari 36 bulan jarang terdeteksi. ${ }^{8,9}$ Kami memilih ASQ:SE2 untuk diuji validitas karena kuesioner ini mudah digunakan (hanya membutuhkan 10 menit) dan dapat mengevaluasi fungsi sosial dan emosional anak usia 1-72 bulan. ${ }^{13}$ Uji validitas ASQ:SE-2 pada 12-36 bulan memenuhi kriteria validitas. Hasil reliabilitas yang cukup baik (diuji dengan Cronbach's alpha) ditemukan pada kelompok usia 18-36 bulan, reliabilitas yang tidak cukup baik ditemukan pada kelompok usia 12 bulan. Dengan demikian, hasil studi ini menunjukkan bahwa ASQ:SE2 dapat digunakan, terutama pada anak di bawah 36 bulan di Indonesia. Kuesioner tervalidasi yang dianggap sesuai dengan usia anak diperlukan untuk melakukan deteksi dini dan memberikan intervensi dini untuk mengatasi gangguan sosio-emosional. Namun, belum dapat memenuhi kebutuhan skrining untuk anak di bawah usia 18 bulan.

Sebanyak 659 subjek dianggap merepresentasikan populasi anak usia 12-36 bulan yang didominasi oleh perempuan dari kelompok usia 36 bulan. Data sensus Jawa Barat pada tahun 2010 menunjukkan populasi usia 0-4 tahun merupakan kelompok usia tertinggi kedua di Jawa Barat setelah kelompok usia 5-9 tahun. Berbeda dengan studi ini, data sensus Jawa Barat pada tahun 2010 menunjukkan lebih banyak laki-laki dibandingkan perempuan pada kelompok usia 0-4 tahun. ${ }^{14}$ Perkembangan kognitif dan sosial dini berhubungan dengan tingkat pendidikan orangtua. Nilai kognitif yang tinggi berhubungan secara signifikan dengan tingkat pendidikan orangtua yang lebih tinggi. ${ }^{15}$ Pada studi ini, tingkat tingkat pendidikan terbanyak adalah sekolah menengah atas (SMA), diikuti dengan diploma, sekolah menengah pertama (SMP), sekolah dasar (SD), dan sarjana.

Perkembangan sosial emosional didefinisikan sebagai kapasitas perkembangan seseorang dari lahir hingga berusia 5 tahun dalam membentuk hubungan dan mengatur emosi. ${ }^{16}$ Pada jangka waktu singkat, anak yang tidak mengalami perkembangan sosial dan emosional yang sesuai cenderung memiliki keterbatasan dalam belajar dan dapat dikeluarkan dari pembelajaran. ${ }^{17}$ Pada jangka panjang, mereka memiliki risiko yang lebih tinggi untuk memiliki gangguan mental, delikuensi, capaian prestasi sekolah yang buruk, dan kesehatan fisik yang kurang baik saat dewasa. ${ }^{18}$ Gangguan sikap dan perilaku pada anak dibagi menjadi dua kategori umum, yaitu gangguan eksternalisasi dan internalisasi. Gangguan eksternalisasi merupakan gangguan ke arah luar dari diri anak yang mencakup perilaku acting-out, menantang, dan perilaku tidak patuh. Gangguan internalisasi lebih bersifat ke dalam diri sendiri yang meliputi penarikan diri, depresi, dan kecemasan. ${ }^{16}$ The American Academy of Pediatrics 
(AAP) merekomendasikan pengawasan pada semua kunjungan anak sehat, dikombinasi dengan skrining terstandardisasi untuk keterlambatan perkembangan pada usia 9, 18, dan 30 (atau 24) bulan, juga saat kunjungan anak yang dicurigai mengalami keterlambatan perkembangan. ${ }^{19}$ Layanan pediatrik komunitas berperan penting untuk identifikasi awal masalah psikososial pada anak karena seringnya interaksi dengan masyarakat. ${ }^{3}$

Kami juga melakukan penilaian menggunakan metode split-half dan menunjukkan hasil yang lebih baik dibandingkan dengan Cronbach's alpha. Hal ini mungkin disebabkan karena penilaian dilakukan dengan dua instrumen terpisah, item invalid tidak diikutsertakan dan uji korelasi antara kedua item dilakukan. Kami hanya melakukan pengujian ulang pada ketiga kelompok usia tersebut karena memiliki hasil yang cukup baik pada reliabilitas dengan menggunakan Cronbach's alpha maupun metode split-half. Metode split-half digunakan sebagai metode statistik untuk menilai konsistensi internal percobaan. ${ }^{6}$

Penggunaan metode split-half sebagai tambahan dari Cronbach's alpha digunakan untuk menguji konsistensi internal kuesioner secara lebih jauh. Reliabilitas pengujian ulang (retest) dievaluasi menggunakan koefisien Pearson berdasarkan kuesioner yang diisi pada waktu 1 dan waktu 2 pada sekelompok orangtua (yang merupakan bagian dari kelompok usia 24, 30, dan 36 bulan) yang setuju untuk ikut serta pada percobaan selanjutnya. Keputusan untuk memberikan rentang waktu 1-3 minggu antara waktu 1 dan waktu 2 didasari oleh usaha meminimalisir maturasi perkembangan anak (mis. tidak lebih dari 3 minggu) sekaligus memastikan bahwa adanya jarak waktu yang cukup antara kedua percobaan agar orangtua tidak mengisi kuesioner berdasarkan ingatan jawaban mereka pada percobaan pertama. Koefisien Pearson untuk semua interval usia berkisar sekitar 0,919 pada usia 24 bulan, 0,897 pada 30 bulan, dan 0,843 pada usia 36 bulan.

Kuesioner yang tervalidasi dapat meningkatkan identifikasi gangguan psikososial pada pelayanan komunitas anak. ${ }^{5}$ Kuesioner yang pendek dan praktis merupakan aset penting untuk mendiagnosis dan menangani gangguan perilaku pada anak secara dini, misalnya, Children Behavioral Checklist (CBCL). Namun, kuesioner ini dinyatakan kurang baik untuk digunakan sebagai instrumen skrining, walaupun validitas dan reliabilitasnya tinggi. Pengisian kuesioner ini membutuhkan waktu lama untuk digunakan pada praktik klinis maupun instrumen skrining rutin. ${ }^{16}$ Validitas ASQ:SE-2 untuk kelompok usia 12-36 bulan telah memenuhi kriteria validitas. Apabila dibandingkan dengan versi Korea dan Turki, validitas dan reliabilitas ASQ:SE-2 versi Indonesia tidak jauh berbeda dari Turki dan Korea. ${ }^{17,18,20}$

Untuk versi Indonesia, ASQ:SE-2 memiliki hasil serupa terkait reliabilitas dan validitasnya. Hasil penilaian menunjukkan instrumen ini memiliki hasil yang baik pada reliabilitas test-retest untuk jarak waktu 1-3 minggu, reliabilitas inter-rater, validitas konkuren, dan sensitivitas dalam mendeteksi keterlambatan perkembangan dan gangguan sosio-emosional yang membutuhkan rujukan. Instrumen ini merupakan pendamping kuesioner ASQ:SE yang secara luas digunakan di AS dan negara lainnya (Korea, Kanada, Tiongkok, Turki, dan Australia). ${ }^{7,16,20}$ Instrumen ini juga memiliki hasil yang baik pada spesifisitas dan konsistensi internal. Instrumen ini mudah untuk dinilai dan dianggap memiliki pertanyaan yang sesuai dan mudah untuk orangtua. $4,7,20$

Total subjek 659 orang dianggap cukup jika dibandingkan studi preliminari yang dilakukan di Korea Selatan dengan 629 subjek. $^{7}$ Kekurangan dari penelitian yang dilakukan Heo $\mathrm{dkk}^{8}$ adalah analisis berbasis kuesioner yang kurang. Pada penelitian kami, analisis berbasis kuesioner dilakukan tidak hanya melibatkan konsultan tumbuh kembang anak, tetapi juga melibatkan konsultan neurobehaviour, psikolog anak, guru, dan orangtua guna proses adaptasi budaya kuesioner. Nilai Cronbach's alpha ASQ:SE-2 versi Indonesia tidak jauh berbeda dari studi sebelumnya yang dilakukan Korea Selatan dan Turki. Kami berharap penelitian ini dapat dikembangkan dengan adaptasi kultural dan dibandingkan dengan CBCL sebagai standar emas.

Penelitian ini memiliki beberapa kekurangan. Hasil uji validitas menunjukkan hasil yang baik pada semua kelompok usia (12, 18, 24, 30, dan 36 bulan). Demikian pula hasil uji reliabilitas menunjukkan hasil yang baik pada sebagian besar kelompok usia. Namun, hasil uji reliabilitas pada usia 12 bulan menunjukkan hasil yang tidak reliabel. Kemungkinan hal tersebut karena adanya pengaruh perbedaan budaya, bahkan pada penduduk yang relatif homogen (secara kultural) di Jawa Barat, tidak dapat dipastikan. Terlepas dari 
keterbatasan tersebut, ASQ-SE-2 versi Indonesia dianggap sesuai untuk anak usia 18-36 bulan. Studi tambahan pada populasi yang lebih besar dan lebih heterogen mungkin diperlukan agar ASQ-SE versi Indonesia dapat digunakan sebagai alat skrining nasional.

\section{Kesimpulan}

Kuesioner ASQ:SE-2 versi Indonesia untuk kelompok usia 18-36 bulan cukup valid dan dapat dipercaya, sedangkan untuk usia 12-18 bulan hanya memenuhi kriteria validitas. Penelitian ini diharapkan dapat diteliti lebih lanjut sebagai studi adaptasi budaya agar dapat digunakan di Indonesia dengan melibatkan kelompok yang dapat memvalidasi ASQ:SE-2 versi Indonesia lebih lanjut.

\section{Daftar pustaka}

1. Hoskins NM. Nelson Textbook of Pediatrics. Edisi ke-18. American Journal of Health-System Pharmacy. Philadelphia: Elsevier Health Sciences; 2007.h.90-100.

2. Shonkoff JP, Phillips DA. National Research Council (US) and Institute of Medicine (US) Committee on Integrating the Science of Early Childhood Development. Dalam: Shonkoff JP, Phillips DA, penyunting. From neurons to neighborhoods: the science of early childhood development [Internet]. Washington (DC: National Academies Press (US; 2000. Didapat dari: https://www.ncbi.nlm.nih.gov/books/ NBK225568\%.

3. Conroy MA, Brown WH. Early identification, prevention, and early intervention with young children at risk for emotional or behavioral disorders: Issues, trends, and a call for action. Behav Disord 2004;29:224-36.

4. Squires J, Bricker D, Twombly E, dkk. Ages \& stages questionnaires, social-emotional (ASQ: SE): A parentcompleted, child-monitoring system for social-emotional behaviors [Internet]. Brookes Publishing Company; 2001. Didapat dari: https://www.researchgate.net/ publication/272824375_Ages_Stages_Questionnaires_SocialEmotional_ASQ_SE_A_Parent-Completed_Child-Monitoring System_for_Social-Emotional_Behaviors.

5. Vogels AG, Crone MR, Hoekstra F, Reijneveld SA. Comparing three short questionnaires to detect psychosocial dysfunction among primary school children: A randomized method. BMC Pub Health 2009;9:489.

6. Warrens MJ. On Cronbach's alpha as the mean of all split-half reliabilities. Dalam: Millsap RE, Bolt DM, van der Ark LA, Wang W-C, penyunting. Springer Proceedings in Mathematics and Statistics. Cham: Springer International Publishing; 2015.h.293-300.

7. Hartini S, Hapsara S, Herini SE, Takada S. Verifying the Indonesian version of the Child Behavior Checklist. Pediatr Int 2015;57:936-41.

8. Heo KH, Squires J. Cultural adaptation of a parent completed social emotional screening instrument for young children: Ages and stages questionnaire-social emotional. Early Hum Dev 2012;88:151-8.

9. Goodman R, Renfrew D, Mullick M. Predicting type of psychiatric disorder from Strengths and Difficulties Questionnaire (SDQ) scores in child mental health clinics in London and Dhaka. Eur Child Adolesc Psychiatry 2000;9:129-34.

10. Egger HL, Erkanli A, Keeler G, Potts E, Walter BK, Angold A. Test-retest reliability of the Preschool Age Psychiatric Assessment (PAPA). J Am Acad Child Adolesc Psychiatry 2006;45:538-49.

11. Lavigne J V, Arend R, Rosenbaum D, Binns HJ, Christoffel KK, Gibbons RD. Psychiatric disorders with onset in the preschool years: I. Stability of diagnoses. J Am Acad Child Adolesc Psychiatry 1998;37:1246-54.

12. Murray DW. Treatment of preschoolers with attention-deficit/ hyperactivity disorder. Curr Psychiatry Rep. 2010;12:374-81.

13. Pontoppidan M, Nissa NK, Pejtersena JH, Julianc MM, Væverd MS. Parent report measures of infant and toddler social-emotional development: A systematic review. Fam Pract 2017;34:127-37.

14. Bagner DM, Rodríguez GM, Blake CA, Linares D, Carter AS. Assessment of Behavioral and Emotional Problems in Infancy: A Systematic Review. Clin Child Fam Psychol Rev 2012;15:113-28.

15. Roberts E, Bornstein MH, Slater AM, Barrett J. Early cognitive development and parental education. Infant Child Dev 1999;8:49-62.

16. Holland ML, Malmberg J, Peacock GG. Emotional and behavioral problems of young children: effective interventions in the preschool and kindergarten years. Edisi ke-2. New York: The Guilford Press; 2017.h.2-44.

17. Rhoades BL, Warren HK, Domitrovich CE, Greenberg MT. Examining the link between preschool social-emotional competence and first grade academic achievement: The role of attention skills. Early Child Res Q 2011;26:182-91.

18. Essex MJ, Kraemer HC, Armstrong JM, dkk. Exploring 
Citra Cesilia dkk: Validitas dan reliabilitas ages \& stages questionnaire: social-emotional 2 versi Indonesia

risk factors for the emergence of children's mental health problems. Arch Gen Psychiatry 2006;63:1246-56.

19. Brauner CB, Stephens CB. Estimating the prevalence of early childhood serious emotional/behavioral disorders: Challenges and recommendations. Public Health Rep 2006;121:303-10.

20. Sijtsma K, Emons WHM. Advice on total-score reliability issues in psychosomatic measurement. J Psychosom Res 2011;70:565-72. 